\title{
Coordinación del inventario y la contabilidad local
}

\author{
Manuel Cebrián Abellán \\ Jefe del Servicio de Asuntos Generales \\ Diputación Provincial de Albacete
}

Para proceder al estudio de esta cuestión habremos de comenzar por acercarnos al objeto del inventario y de la contabilidad. El inventario es un registro administrativo que recoge el conjunto de bienes y derechos que pertenecen a las Entidades locales. La contabilidad un sistema de registro, elaboración y comunicación de información sobre la actividad económico-financiera y presupuestaria desarrollada por dichas Entidades durante el ejercicio contable. Tan definidos son sus perfiles y tan claras sus finalidades que parecen no tener relación alguna; tanto es así que, tal y como demuestra nuestra presente realidad local, tienden a ignorarse entre ellos.

No sorprende hoy esa situación, pues existen entes locales que incluso incumplen las determinaciones que sobre dichos registros establece la legislación vigente. Los motivos que originan la misma son la carencia de medios. Nos encontramos ante unas Entidades profundamente renovadas, pero agotadas por el esfuerzo económico realizado para corregir el profundo déficit de servicios e infraestructuras que arrastraban; la insuficiencia de medios es uno de los rasgos que las identifican.

Pero esa realidad no puede ocultar que tanto el inventario como la contabilidad tienen un marcado componente patrimonial. El primero recoge, como decimos, el conjunto de bienes y derechos que pertenecen a las Entidades locales. La segunda refleja el inmovilizado de que disponen las mismas. Ese punto de encuentro es el que justifica la necesidad de engarce entre uno y otra. No es ésta, sin embargo, una necesidad advertida en el momento presente, sino planteada ya en épocas anteriores por la doctrina. ChACÓN ORTEGA ${ }^{1}$ alude a la disociación entre el inventario y el patrimonio contable, proponiendo medidas para evitar la misma.

El adecuado engranaje de la actuación administrativa conlleva siempre un ahorro de medios y una más eficaz respuesta a los problemas planteados. La dispersión de esfuerzos resta a la Administración capacidad para una más ágil gestión de las funciones a ella encomendadas. A nadie ya se

\footnotetext{
1 Luis Chacón Ortega: Manual de Procedimiento y Formularios de Bienes, Derechos y Acciones para Ayuntamientos. Editorial Bayer Hnos. S.A. Barcelona 1998. P. 430 a 437.
} 
le escapa que una deficiente conexión de actuaciones va a suponer siempre más gasto - derivado de la distracción de medios- y un peor servicio. El gasto público corriente y la deficiente calidad de los servicios son dos de los males que tradicionalmente han venido aquejando a nuestra Administración, y no debe contribuir la cuestión aquí analizada a profundizar en los mismos, sino a superar el atraso que esta situación representa. El objetivo habrá se ser evitar esa falta de conexión.

Minimizar o dulcificar, bajo cualquier pretexto, el citado problema supone, además de restar importancia a la materia, renunciar a su solución. La dinámica social, y por ende también la pública, obligan a una permanente renovación y puesta al día. Las inercias conducen a la consolidación, por no decir reforzamiento, de situaciones caducas y contrarias a los cambios que la sociedad y Administración demandan. Contribuir a esa renovación significa apostar por una Administración moderna.

Parece, pues, que se impone la coordinación entre los mencionados registros. Según el Diccionario de la Real Academia Española de la Lengua la palabra «coordinar» tiene, entre otras acepciones, la de «concertar medios, esfuerzos, etc., para una acción común». Este concepto académico no difiere del que aquí nos interesa. Por coordinación hemos de entender la facultad de ordenar la acción pública con el fin de alcanzar la coherencia y eficacia administrativa. No hemos de olvidar tampoco que la coordinación cumple también una función no menos relevante que la anterior, cual es la de preservar la unidad de la Administración, evitando la existencia de ámbitos estancos dentro de la misma. Pues bien, teniendo en cuenta que tanto el inventario como la contabilidad trascienden el interés propio de las Áreas bajo cuya responsabilidad quedan sometidos y que la coherencia y la eficacia administrativa es uno de los pilares donde se asienta el actuar de la Administración, la coordinación se convierte en necesario presupuesto para la formulación de ambos registros.

Tanto interesa el logro de la eficacia de la Administración, que nuestra Carta Magna, en su artículo 103.1, incluye a la coordinación como uno de los principios que han de regir el actuar de la misma. Los artículos 6.1 de la LRBRL y 3.1 de la LRJPAC se hacen eco igualmente de ese mismo principio. Se coloca, por tanto, aquél, y al máximo nivel normativo en el Ordenamiento jurídico, en referente para el logro de la eficacia en la acción pública.

Aunque la coordinación es, como vemos, uno de los principios que inspiran la actuación de la Administración, su traducción práctica no siempre está exenta de dificultades. El marcado tecnicismo de los asientos y 
anotaciones reflejadas en los registros de que se trata son ya una clara manifestación de la complejidad de la materia. En nuestra opinión, le aventuramos a la misma una difícil puesta en escena, por no decir escasa respuesta, y ello por las razones que pasamos a exponer:

a) Por la insuficiente determinación legal. En el RB no se contienen previsiones sobre el particular.

Dejando a un lado, ante la pérdida de vigencia, las Instrucciones de Contabilidad de 17 de julio de $1990^{2}$, las únicas referencias que encontramos en la normativa local resultan de las Ordenes EHA/4041/2004 y EHA/4042/2004, de 23 de noviembre, por las que se aprueban las Instrucciones de Contabilidad local en sus modelos normal y simplificado, respectivamente ${ }^{3}$. La entrada en vigor de dichas Ordenes e Instrucciones será el día 1 de enero de 2006.

La regla 16 de la Instrucción de Contabilidad, modelo normal, y la 17 de la Instrucción de Contabilidad, modelo simplificado, establecen la siguiente igual previsión:

«Regla 16/17. Inventario.

1. La entidad contable deberá contar con el oportuno Inventario de bienes y derechos que, de conformidad con la legislación patrimonial, detalle de forma individual los diversos elementos del inmovilizado que tiene registrados en su contabilidad.

2. En el caso de que no exista la necesaria coordinación entre la contabilidad y el Inventario General, la entidad deberá contar con un inventario específico, de carácter contable, para detallar individualmente su inmovilizado».

\footnotetext{
2 Las Instrucciones de Contabilidad de 1990 eran de aplicación al conjunto de la Administración local. Existía una Instrucción para las Entidades locales cuyo ámbito territorial tuviera una población superior a 5.000 habitantes $-\mathrm{IC}-$, y otra para las que tuviesen una población inferior a dicha cifra -IC-5-.

3 Las Instrucciones de contabilidad son de aplicación al conjunto de la Administración local. Más concretamente, el ámbito de aplicación de las mismas es el siguiente:

- Modelo Normal: municipios cuyo presupuesto exceda de $3.000 .000 €$ y aquellos cuyo presupuesto no supere este importe pero exceda de $300.000 €$ y cuya población sea superior a 5.000 habitantes; demás Entidades locales siempre que su presupuesto exceda de 3.000.000 €; y organismos autónomos dependientes de las Entidades locales referidas.
}

- Modelo Simplificado: municipios cuyo presupuesto no exceda de $300.000 €$ y aquellos cuyo presupuesto supere este importe pero no exceda de $3.000 .000 €$ y cuya población no supere 5.000 habitantes; demás Entidades locales siempre que su presupuesto no exceda de 3.000.000 €; y organismos autónomos dependientes de las Entidades locales citadas.

Además de los Modelos Normal y Simplificado, existe un Modelo Básico, aprobado por Orden EHA/4040/2004, que es de aplicación a las Entidades locales cuyo presupuesto no exceda de 300.000 $€$. Este Modelo es de aplicación voluntaria para aquellas Entidades locales de muy pequeña dimensión. En el mismo no se hace referencia alguna a la coordinación entre inventario y contabilidad. 
La regulación contenida en dichas reglas es insuficiente y desacertada. Es insuficiente porque esa necesaria coordinación debiera también estar prevista, además de en las Instrucciones de contabilidad citadas, en el RB, con fijación en ambas normas de pautas para llevarla a cabo. La estructura que otorgan dichas normas a las materias por ellas reguladas, y más específicamente a la estructura del inventario en el RB y al inmovilizado en las Instrucciones de contabilidad, difiere sustancialmente.

\section{Estructura del inventario en el Reglamento de Bienes: art. 18.}

1. Inmuebles

2. Derechos reales

3. Muebles de carácter histórico, artístico o de considerable valor económico

4. Valores mobiliarios, créditos y derechos de carácter personal de la Corporación

5. Vehículos

6. Semovientes

7. Muebles no comprendidos en los anteriores enunciados

8 . Bienes y derechos revertibles

\begin{tabular}{|c|c|}
\hline $\begin{array}{l}\text { Estructura del inmovilizado en la } \\
\text { Instrucción contabilidad modelo normal: } \\
\text { Grupo } 2 \text {. }\end{array}$ & $\begin{array}{l}\text { Estructura del inmovilizado en la } \\
\text { Instrucción contabilidad modelo } \\
\text { simplificado: Grupo } 2 .\end{array}$ \\
\hline $\begin{array}{l}\text { 20. INVERSIONES DESTINADAS } \\
\text { AL USO GENERAL. } 200 \text { Terrenos y } \\
\text { bienes naturales. 201 Infraestructuras y } \\
\text { bienes destinados al uso general. } 202 \\
\text { Bienes comunales. 208 Bienes del } \\
\text { patrimonio histórico, artístico y cultural. }\end{array}$ & $\begin{array}{l}\text { 20. INVERSIONES DESTINADAS } \\
\text { AL USO GENERAL. 200 Terrenos y } \\
\text { bienes naturales. 201 Infraestructuras y } \\
\text { bienes destinados al uso general. 202 } \\
\text { Bienes comunales. 208 Bienes del } \\
\text { patrimonio histórico, artístico y cultural. }\end{array}$ \\
\hline \begin{tabular}{l}
\multicolumn{1}{c}{21.} \\
INMOVILIZACIONES \\
INMATERIAES. 210 Gastos de \\
investigación y desarrollo. 212 Propiedad \\
industrial. 215 Aplicaciones informáticas. \\
216 Propiedad intelectual. 217 Derechos \\
sobre bienes en régimen de arrendamiento \\
financiero. 218 Aprovechamientos \\
$\begin{array}{l}\text { urbanísticos. } \\
\text { inmaterial. }\end{array}$
\end{tabular} & \begin{tabular}{l}
\multicolumn{1}{c}{21.} \\
INMOVILIZACIONES \\
$\begin{array}{l}\text { INMATERIALES. } \\
\text { inmaterial. }\end{array}$
\end{tabular} \\
\hline \begin{tabular}{lr}
22. & \multicolumn{2}{c}{ INMOVILIZACIONES } \\
MATERIALES. 220 Terrenos y bienes \\
naturales. $221 \quad$ Construcciones. 222 \\
Instalaciones técnicas. 223 Maquinaria. 224 \\
Utillaje. 226 Mobiliario. 227 Equipos para \\
procesos de información. 228 Elementos de \\
transporte. 229 Otro inmovilizado material.
\end{tabular} & $\begin{array}{l}22 . \\
\text { MNMOVILIZACIONES } \\
\text { MATERIALES. } 220 \text { Terrenos y bienes } \\
\text { naturales. 221 Construcciones. } 222 \\
\text { Instalaciones técnicas. 223 Maquinaria y } \\
\text { utillaje. 226 Mobiliario. 227 Equipos para } \\
\text { procesos de información. } 228 \text { Elementos } \\
\text { de transporte. 229 Otro inmovilizado } \\
\text { material. }\end{array}$ \\
\hline
\end{tabular}




\begin{tabular}{|c|c|}
\hline $\begin{array}{l}\text { 23. INVERSIONES GESTIONADAS } \\
\text { PARA OTROS ENTES PÚBLICOS. } 230 \\
\text { Inversiones gestionadas para otros entes } \\
\text { públicos. }\end{array}$ & \\
\hline 24. PATRIMONIO PÚBLICO DEL & 24. PATRIMONIO PÚBLICO DEL \\
\hline $\begin{array}{l}\text { SUELO. } 240 \quad \text { Terrenos. } \\
\text { Construcciones. } 242 \text { Aprovechamientos } \\
\text { urbanísticos. 249 Otros bienes y derechos } \\
\text { del Patrimonio Público del Suelo. }\end{array}$ & $\begin{array}{l}\text { SUELO. } 240 \quad \text { Terrenos. } \\
\text { Construcciones. } 242 \text { Aprovechamientos } \\
\text { urbanísticos. 249 Otros bienes y derechos } \\
\text { del Patrimonio Público del Suelo. }\end{array}$ \\
\hline $\begin{array}{l}\text { 25. INVERSIONES FINANCIERAS } \\
\text { PERMANENTES. 250. Inversiones } \\
\text { financieras permanentes en capital. } 251 \\
\text { Valores de renta fija. } 252 \text { Créditos a largo } \\
\text { plazo. } 253 \text { Créditos a largo plazo por } \\
\text { enajenación de inmovilizado. } 254 \\
\text { Operaciones de intercambio financiero. } \\
25430 \text { Diferencias deudoras en operaciones } \\
\text { de intercambio financiero de divisas. } 256 \\
\text { Intereses a largo plazo de valores de renta } \\
\text { fija. } 257 \text { Intereses a largo plazo de créditos. } \\
259 \text { Desembolsos pendientes sobre } \\
\text { acciones. }\end{array}$ & $\begin{array}{l}\text { 25. INVERSIONES FINANCIERAS } \\
\text { PERMANENTES. } \quad 250 \text { Inversiones } \\
\text { financieras permanentes. }\end{array}$ \\
\hline $\begin{array}{l}\text { 26. FIANZAS Y DEPÓSITOS } \\
\text { CONSTITUIDOS A LARGO PLAZO. } 260 \\
\text { Fianzas constituidas a largo plazo. } 265 \\
\text { Depósitos constituidos a largo plazo. }\end{array}$ & $\begin{array}{l}\text { 26. FIANZAS } \text { Y DEPÓSITOS } \\
\text { CONSTITUIDOS A LARGO PLAZO. } \\
260 \text { Fianzas y depósitos constituidos a } \\
\text { largo plazo. }\end{array}$ \\
\hline $\begin{array}{l}\text { 27. GASTOS A DISTRIBUIR EN } \\
\text { VARIOS EJERCICIOS. 270 Gastos de } \\
\text { formalización de deudas. } 271 \text { Gastos } \\
\text { financieros diferidos de valores } \\
\text { negociables. } 272 \text { Gastos financieros } \\
\text { diferidos de otras deudas. } 279 \text { Otros gastos } \\
\text { amortizables. }\end{array}$ & $\begin{array}{l}\text { 27. GASTOS A DISTRIBUIR EN } \\
\text { VARIOS EJERCICIOS. } 270 \text { Gastos a } \\
\text { distribuir en varios ejercicios. }\end{array}$ \\
\hline $\begin{array}{l}\text { 28. AMOTIZACIÓN ACUMULADA } \\
\text { DEL INMOVILIZADO. } 281 \text { Amortización } \\
\text { acumulada del inmovilizado inmaterial. } 282 \\
\text { Amortización acumulada del inmovilizado } \\
\text { material. } 284 \text { Amortización acumulada del } \\
\text { Patrimonio Público del Suelo. }\end{array}$ & $\begin{array}{l}28 . \\
\text { AMOTIZACIÓN } \\
\text { ACUMULADA DEL INMOVILIZADO. } \\
281 \text { Amortización acumulada del } \\
\text { inmovilizado inmaterial. } \\
\text { Amortización acumulada del inmovilizado } \\
\text { material. 284 Amortización acumulada del } \\
\text { Patrimonio Público del Suelo. }\end{array}$ \\
\hline 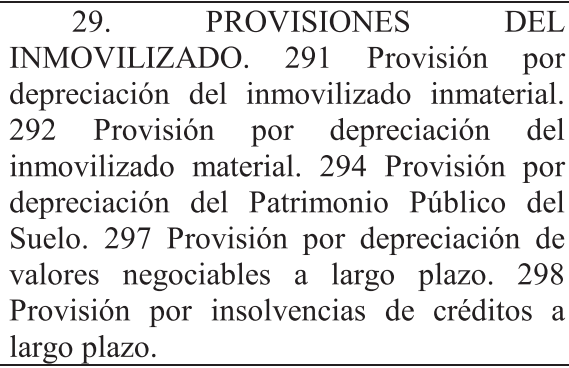 & \\
\hline
\end{tabular}


Y decimos que es desacertada porque, tras imponer a las Entidades locales la obligación de coordinar inventario y contabilidad, admite que esa coordinación no se produzca, estableciendo en tal caso la obligación de formular un inventario específico de carácter contable.

Más adecuada nos parecía la regulación contenida en las Instrucciones de Contabilidad de 1990 -reglas 202 de la IC y 135 del IC-5-, que, sin contener referencia alguna a la obligación de formular inventario específico de carácter contable, apuntaban en la línea de la coordinación de los registros citados. La inexistencia en dichas Instrucciones de alternativas a la coordinación de ambos registros les otorgaba una mayor virtud, pues no permite solución distinta que el engarce del inventario y la contabilidad.

b) - Por el diferente reparto de responsabilidades. La responsabilidad sobre el inventario y contabilidad viene atribuida, respectivamente, a la Secretaría y a la Intervención ${ }^{4}$. Conforme a lo determinado en los artículos 2. j) del R.D. 1174/87, de 18 de septiembre, y 32.1 del RB corresponde a la Secretaría llevar y autorizar el inventario. Por su parte, el artículo 204 del TRLRHL atribuye la función contable a la Intervención. Salvo en las Entidades de menor tamaño, en el que ambas funciones recaen en el mismo puesto, este reparto de las mismas contribuye a la falta de conexión y engarce a que nos referimos.

El legislador ha tenido especial celo, en consonancia con la importancia de las citadas materias, en atribuir a la Secretaria e Intervención esas responsabilidades, pero ha descuidado la coordinación de las mismas. El factor de progreso y modernidad que ese engarce supone no ha tenido tampoco acogida en las expresadas normas.

c)- Por la complejidad formal. Si a las exigencias impuestas por el RB y por el TRLRHL e Instrucciones de Contabilidad en orden, respectivamente, a la formulación y rectificación del inventario y a llevar la contabilidad se añade la de coordinar uno y otra, no encontramos incentivos para acometer la misma.

Al margen de la valoración que nos pueda merecer la regulación contenida en dichas Instrucciones, lo cierto es que en éstas se impone a las Enti-

\footnotetext{
${ }^{4}$ Las Orden EHA/4041/2004, por la que se aprueba la Instrucción del modelo normal de Contabilidad Local, alude también a las funciones de contabilidad de los órganos de la Entidad local que la tengan atribuida en los municipios de gran población.

Ha de advertirse que, tras la reforma de la LRBRL, llevada a efecto mediante la Ley 57/2003, de 16 de diciembre, se han separado en esos municipios las funciones de contabilidad y control interno de la gestión económico-financiera.
} 
dades locales la obligación de reflejar en el inventario los diversos elementos del inmovilizado registrados en su contabilidad. No es ésta una cuestión fácil de resolver, pues, como decimos, no existen determinaciones sobre el particular. Habrá que acudir, por tanto, al certero criterio del personal local para solventar las dificultades que se presenten. Las cuestiones económicas van a adquirir un elevado protagonismo. Aspectos tales como las amortizaciones del inmovilizado habrán de ser tenidos también en cuenta.

Ante la necesidad y la obligatoriedad de tener en cuenta tanto la estructura establecida por el RB como por la fijada en las Instrucciones de Contabilidad, la Enciclopedia La Administración Práctica ${ }^{5}$ propone un híbrido entre las determinaciones recogidas en ambas normas, partiendo siempre de la numeración contenida en las Instrucciones, excepto para los casos en los que los conceptos del RB no tienen referente en el Grupo 2 del plan de cuentas, en cuyo caso sugiere utilizar las cifras del mencionado Reglamento -3. Muebles de carácter histórico, 6. Semovientes, y 7. Muebles no comprendidos en los anteriores parágrafos-.

d)- Por la deficiente garantía de los servicios en los que recae la referida responsabilidad. La situación de precariedad en la que habitualmente se desenvuelven los entes locales llega incluso a la imposibilidad por algunos pequeños municipios ${ }^{6}$ de costear algo tan básico y necesario como el puesto de Secretaría-Intervención, en quien recae, como ya hemos visto, la responsabilidad de la materia analizada.

La normativa reguladora sobre el particular, recogida en el Real Decreto $1732 / 1994$, de 29 de julio, sobre provisión de puestos de trabajo de funcionarios de Administración local con habilitación de carácter nacional, en línea con la regulación en materia de Régimen Local, no resuelve el asunto, sino que se limita a apuntalarlo; su objetivo es poco ambicioso, sólo pretende garantizar unos servicios mínimos de la indicada naturaleza. Según resulta de su contenido, los municipios se verán abocados, en el mejor de los casos, a constituir, con otros municipios en igual situación, una agrupación para el sostenimiento en común del referido puesto y, en el peor de aquéllos, a solicitar de la correspondiente Comunidad Autónoma que sean eximidos de la obligación de mantener dicho puesto, en cuyo

\footnotetext{
${ }^{5}$ Criterio de los redactores de la Enciclopedia La Administración Práctica -editada por Bayer Hnos.S.A.-, contenido en artículo que gira bajo el título «Expediente para la aprobación del inventario de bienes de una entidad local, II» (cuaderno 4, abril 2005). P. 250.

${ }^{6}$ Según las cifras de población resultantes de la revisión del Padrón municipal referidas a 1 de enero de 2004 -declaradas oficiales por Real Decreto 2348/2004, de 23 de diciembre-, en España 5.889 municipios -de los 8.109 existentes- tienen menos de 2.000 habitantes.
} 
caso el municipio podrá solicitar de éstas la acumulación de dichas funciones a funcionarios con habilitación nacional que se encuentren ocupando puesto en otra Entidad local próxima, o bien esperar al ejercicio de las mismas por las Diputaciones provinciales, Cabildos, Consejos Insulares o entes supramunicipales, a través de sus Servicios de Asistencia.

Lo realmente grave de esta regulación no es la escasa ambición de objetivos, sino privar al municipio de unos servicios, con dedicación plena y exclusiva, imprescindibles para el normal funcionamiento del mismo, servicios que cada día se manifiestan más necesarios a la vista de la complejidad que presenta la actual vida y marco normativo local.

e)- Por la carencia de soporte instrumental adecuado. La LRJPAC determina en su artículo 45.1 que «Las Administraciones públicas impulsarán el empleo y aplicación de las técnicas y medios electrónicos, informáticos y telemáticos para el desarrollo de su actividad y el ejercicio de sus competencias.....», pero la recepción a nivel normativo en orden a la incorporación por las Administraciones de medios técnicos no se ha traducido siempre en la existencia de los programas informáticos precisos y del personal especializado necesario para que dicha determinación pueda ser una verdadera realidad. La informatización de los entes locales no ha ido siempre acompañada de la permanente y continua adaptación de sus equipos a las necesidades reales de los mismos.

Las Diputaciones provinciales y las Asociaciones de entes locales vienen prestando un decidido apoyo a los municipios en esta materia de índole instrumental, si bien el gran número de municipios existentes -8.109-, las múltiples y variadas necesidades de los mismos y los también limitados recursos de aquéllas hace que su actuación no sea siempre el remedio a los problemas de los entes a los que prestan asistencia.

La decidida apuesta que se realiza en las Instrucciones de Contabilidad de cara a la incorporación de técnicas electrónicas, informáticas y telemáticas en la función contable -reglas 13 y 14 del modelo normal y 14 y 15 del simplificado- no se ha traducido, sin embargo, en referencias precisas para llevar a cabo la coordinación entre los registros referidos. Según las previsiones que en dichas Instrucciones se establecen en orden a la configuración informática del $\mathrm{SICAL}^{7}$ que adopte cada entidad con-

\footnotetext{
${ }^{7}$ El SICAL se configura en las Instrucciones de Contabilidad como «..... un conjunto integrado de subsistemas o áreas contables que debe garantizar la concordancia, exactitud y automatismo de los registros que, para cada una de las operaciones contables, se deban producir en los distintos subsistemas a los que la operación afecte, así como a la existencia de la debida coherencia entre los distintos niveles de información, tanto agregados como de detalle».
} 
table, ésta ha de responder a los siguientes criterios: estará orientada al cumplimiento del objeto y fines del mismo -como, y en lo que aquí interesa, a posibilitar el inventario y el control del inmovilizado-; deberá garantizar la integridad, coherencia, exactitud y automatismo de las anotaciones contables; deberá existir la debida concordancia entre los distintos niveles de información; deberá propiciar la simplificación de los procedimientos contables; y deberá aplicarse las medidas de seguridad de datos de carácter personal. La generalidad de tales criterios, sin mención específica alguna a la coordinación de dichos registros, otorga excusa suficiente a las Entidades locales para eludir esa responsabilidad.

f)- Por la resistencia a modificar la estructura establecida. En la Administración siempre existen elementos de resistencia que obstaculizan $\mathrm{o}$, al menos, demoran la aplicación de las reformas o modificaciones introducidas. El conocimiento de lo ya existente y las dificultades o, en el mejor de los casos, incomodidades que conllevan los cambios introducidos es el origen de aquélla.

Debe hacerse un importante esfuerzo por el personal de las Entidades locales en orden a la coordinación del inventario y la contabilidad, esfuerzo que no va encontrar el más mínimo apoyo normativo -debido a las inexistentes pautas sobre la materia- ni aliento del cuerpo político de la Entidad -que entiende como de responsabilidad del anterior cualquier cuestión de índole formal-. Habrá que estar, por tanto, al buen hacer de Secretarios e Interventores -u órganos de la Entidad local que tengan atribuida las funciones de contabilidad en los municipios de gran poblaciónpara que las nuevas Instrucciones de Contabilidad vean cumplido el mandato en ellas contenido sobre la coordinación aludida.

Todos estos argumentos no vienen a descubrir nada nuevo sobre la vida local. Pretenden relacionar determinadas circunstancias y situaciones con la materia analizada. Las conclusiones que de ellos se puedan extraer son diversas, si bien nosotros hemos de quedarnos con algunas que consideramos de más interés.

A nuestro juicio, las nuevas Instrucciones de Contabilidad refrendan la influencia que viene a ejercer la Intervención, a través de la vía de la coordinación, en la elaboración del inventario. Aun quedando éste bajo la responsabilidad de la Secretaría, el creciente peso de la Intervención en la vida de la Entidad se dejará sentir también en esta materia.

La coordinación del inventario y la contabilidad va a suponer un notable esfuerzo de tiempo e imaginación para el personal de las Entidades 
locales, que esperemos esté en disposición de realizar. Lo contrario sería duplicar el trabajo, pues llevaría consigo la formulación de un inventario específico de carácter contable, con la consiguiente distracción de medios y pérdida de eficacia en la actuación administrativa.

El inventario tendrá que dejar penetrar las determinaciones de las Instrucciones de Contabilidad en la conformación de su propia estructura, con acomodación de la misma a la del inmovilizado de su contabilidad. El RB se ve superado, a través de dichas Instrucciones, en cuanto a sus contenidos, no siendo ya el único referente normativo para la elaboración del inventario.

Por último, señalar que las Instrucciones de Contabilidad han desaprovechado una extraordinaria oportunidad para avanzar en esa necesaria coordinación. La formulación de un inventario específico de carácter contable representa la renuncia definitiva a la misma. Se viene a reconocer, en definitiva, las dificultades que existen para que esa conexión se produzca, sin la adopción de medida alguna en favor de ésta; es más con la introducción de elementos desincentivadores para que la coordinación sea una verdadera realidad. 